\title{
Complexificando a interseccionalidade: Perspectivas queer sobre o mundo do trabalho
}

\section{Benito Bisso Schmidt ${ }^{\star}$}

Resumo: A noção de interseccionalidade possibilitou complexificar o entendimento dos processos de dominação e resistência nas sociedades contemporâneas ao entender as opressões como co-constitutivas, articuladas e não hierarquizadas, ao menos a priori. Na historiografia do trabalho, tal perspectiva tem enfocado especialmente os cruzamentos das dominações e discriminações de gênero, raça-etnia e classe. Porém, ainda são poucas as pesquisas que se voltam para os trabalhadores sexualmente desviantes dos padrões heteronormativos. Menos visíveis até pelo próprio caráter de segredo que historicamente as constituem, as experiências desses desviantes sexuais e os discursos que os configuram também são formadores do mundo do trabalho. Basta pensar, por exemplo, nas profissões socialmente estabelecidas como próprias de pessoas queer (como as de cabeleireiro, estilista, comissário de bordo e enfermeiro) ou no reforço da heteronormatividade nas atividades de militância sindical e política, com seus apelos, explícitos ou velados, a valores ligados às masculinidades hegemônicas. Esta comunicação pretende chamar atenção para a importância de se levar em conta a referida perspectiva analítica, bem como apontar alguns caminhos historiográficos e metodológicos possíveis para a sua efetivação.

Palavras-chave: interseccionalidade; pessoas LGBTQ; heteronormatividade.

Abstract: The notion of intersectionality made it possible to complexify the understanding of the processes of domination and resistance in contemporary societies by understanding oppressions as co-constitutive, articulated and nonhierarchical, at least a priori. In the historiography on labor, this perspective has focused especially the crossings of the dominations and discriminations of gender, race-ethnicity and class. However, there is still very little research on workers with sexuality deviant from heteronormative patterns. Less visible even by the very

\footnotetext{
Doutor em História Social pela Universidade Estadual de Campinas (Unicamp). Professor Titular do Departamento de História e do Programa de Pós-Graduação em História da Universidade Federal do Rio Grande do Sul (UFRGS) e do Mestrado Profissional em Ensino de História (PROFHISTÓRIA). Bolsista de Produtividade do CNPq. Trabalho elaborado durante a realização de estágio sênior na Universidade de Brown (EUA), com bolsa da CAPES. A primeira versão deste artigo foi apresentada na mesa-redonda "Raça, gênero e classe na história social do trabalho: visões interseccionais", durante o V Seminário Internacional Mundos do Trabalho do GT Mundos do Trabalho da Associação Nacional de História (ANPUH-Brasil). Agradeço aos(às) organizadores(as) e aos(às) colegas que participaram do debate que se seguiu à apresentação. E-mail: bbissos@yahoo.com.
} 
character of secret that historically constitutes them, the experiences of these sexual deviants, and the speeches that configure them are also constitutive of the world of labor. It is sufficient to think, for example, of the socially established "queer professions" (such as hairdressers, stylists, flight attendants and nurses) or reinforcing heteronormativity in trade union and political activism, with their explicit or veiled demands to values related to hegemonic masculinities. This article intends to call attention to the importance of taking into account this analytical perspective, as well as to point out some possible historiographic and methodological paths for its effectiveness.

Keywords: intersectionality; LGBTQ people; heteronormativity.

E m 1895, o influente jurista Francisco José Viveiros de Castro, considerado o maior especialista da época no combate aos crimes sexuais, em seu estudo intitulado "Atentados ao pudor: sobre as aberrações do instinto sexual", caracterizou psicologicamente os "pederastas" como histéricos, passionais, egoístas, vaidosos, inconstantes, instáveis, covardes e ciumentos ao extremo. Fisicamente eram identificados pela "ausência de pelos", por "longos cabelos, geralmente louros e cuidadosamente anelados", pela "palidez da pele e ausência de vigor físico", pelo "olhar oblíquo e o ar cínico", além do "gosto por roupas de cores vivas" e pelo "uso de perfumes". Mais ainda, assim como as "tribades" (lésbicas) tendiam a não aceitar a vida e as tarefas do lar, os "pederastas" se recusariam a exercer profissões "que demandavam qualidades viris", preferindo as atividades de alfaiates, modistas, lavadeiros, engomadores, cabeleireiros e floristas, entre outras.'

Mais de 30 anos depois, Leonídio Ribeiro, médico criminalista, professor de medicina legal, diretor do Gabinete de Identificação da Polícia Civil do então Distrito Federal e criador, nessa mesma instituição, de um Laboratório de Antropologia Criminal, publicou, no número de julho-agosto de 1935 da Revista Brasileira - Síntese do Momento Internacional, o artigo "Homossexualismo e Endocrinologia". Nele explica que, no referido laboratório, foram estudados 14.312 "homossexuais" "sob o ponto de vista biotipológico". Esses indivíduos foram todos detidos em casas de prostituição, algumas exclusivamente masculinas, pelo delegado dr. Dulcídio Gonçalves. Dos casos examinados, 86 eram de cor branca, 50 mestiços e 7 pretos. As profissões frequentemente encontradas eram: trabalhos domésticos, em número de 63, e mais 25 do comércio, 10 operários, 13 alfaiates e 32 de ocupações as mais diversas. ${ }^{2}$

Textos como esses já foram analisados por pesquisadores e pesquisadoras interessados em examinar o discurso médico e legal que legitimou a construção da ordem burguesa no Brasil entre a última década do século XIX e as primeiras do XX. Eles comporiam, junto a outras práticas discursivas e não discursivas, o conjunto de dispositivos responsáveis pela disciplinarização e higienização das cidades empreendidas pelas elites brasileiras, as quais, participando de debates internacionais sobre raça e eugenia, pretendiam delimitar claramente as fronteiras

1 MARTINS JUNIOR, Carlos. "Saber jurídico e homossexualidade no Brasil da Belle Époque”. Diálogos, Maringá, v. 19, n. 3, p. 1217-1251, set.-dez., 2015, p. 1231.

2 RIBEIRO, Leonídio Ribeiro. "Homossexualismo e Endocrinologia” (reproduzido em Revista Latinoamericana Psicopatologia Fundamental, São Paulo, v. 13, n. 3, p. 498-511, setembro, 2010). 
entre a normalidade e a anormalidade, entre o trabalho e o não trabalho, e investir na formação do "bom cidadão", ordeiro e disciplinado. 3 Tais discursos também comparecem como fontes em investigações sobre um eixo específico desse processo mais geral: a história das homossexualidades no país a partir das falas dos "doutores" que oscilavam entre considerar as práticas homoeróticas como crimes ou como sintomas de patologias. ${ }^{4}$

Contudo, parece-me que pouco se levou em conta duas outras potencialidades de pesquisa dos tratados de Viveiros de Castro, Leonídio Ribeiro e outros semelhantes: o de serem também fontes para uma história da branquitude, considerando o grande número dos "pederastas" de cabelos loiros e pele pálida, no caso do estudo de Castro, e a maioria de homossexuais "de cor branca", no caso da pesquisa de Ribeiro; e para a história do trabalho, levanto em conta o fato de que as preferências eróticas das pessoas estudadas por esses doutores foram relacionadas a determinadas ocupações, como aquelas vinculadas à estética e ao trabalho doméstico, mas incluindo também empregados do comércio e mesmo operários. A propósito, quem seriam os 10 operários "homossexuais" examinados por Leonídio? De que maneira as práticas e desejos sexuais desses e de outros trabalhadores com os mesmos desejos e práticas se articularam com as suas experiências de classe (e de raça e de gênero)? Quais as consequências de tais práticas e desejos nos seus relacionamentos com outros operários e operárias que não transgrediam a heteronormatividade? Como o fato de terem sido detidos em casas de prostituição masculina influenciou nas suas vivências públicas e privadas (familiares, profissionais, político-sindicais, de lazer etc.)? Muitas perguntas semelhantes podem ser feitas se examinarmos os sujeitos de nossas pesquisas sem pressupormos uma heterossexualidade compulsória ${ }^{5}$ de todos e todas. Possivelmente uma parte significativa dessas questões fique sem resposta, sobretudo pelo armário, esse "dispositivo de regulação da vida de gays e lésbicas" " que invisibiliza sua presença nas fontes disponíveis, mas talvez, como pretendo defender aqui, enunciá-las talvez não seja sem consequências para a história do trabalho.

Cito agora outro exemplo das raras fontes que encontrei (ainda que a minha busca não tenha sido sistemática) que articulam "desvios sexuais" e história do trabalho, nesse caso, ao mundo sindical, referente a uma temporalidade bem mais próxima da nossa. Almir Dias da Silva, pessoa com deficiência e gay, publicou em 2014 suas memórias no livro intitulado: "Dando pinta: memórias de um homossexual". Ao narrar suas vivências como bancário em Porto Alegre no final da década de 1970, ele afirma:

Naquele tempo eu também participava da política sindical. Acompanhava e fazia todas as greves por melhores salários. Após nos mobilizarmos em frente à agência Centro [do Banrisul], saíamos em caminhada até a Esquina Democrática [cruzamento da Avenida Borges de Medeiros com a Rua dos Andradas, no centro de Porto Alegre] [...]

3 Ver, por exemplo: COSTA, Jurandir Freire Costa. Ordem médica e norma familiar. Rio de Janeiro: Graal, 1979; ENGEL, Magali Gouveia. Meretrizes e doutores: saber médico e prostituição no Rio de Janeiro (18401890). São Paulo: Brasiliense, 1989; RAGO, Margareth. Do cabaré ao lar: a utopia da cidade disciplinar Brasil 1890-1930. São Paulo: Paz e Terra, 1985.

4 Consultar, entre outros: FERLA, Luis Antonio Coelho. "Feios, sujos e malvados: do crime ao trabalho, a utopia médica do biodeterminismo em São Paulo (1920-1945)" (Tese de doutorado em História Econômica, Universidade de São Paulo, 2005); GREEN, James Naylor. Além do carnaval: a homossexualidade masculina no Brasil do século XX. São Paulo: Ed. UNESP, 2000.

5 BUTLER, Judith. Problemas de gênero: feminismo e subversão da identidade. Rio de Janeiro: Editora Civilização Brasileira, 2003.

6 SEDGWICK, Eve Kosofsky. “A epistemologia do armário”. Cadernos Pagu, n. 28, p. 19-54, jan.-jun., 2007, p. 22. 
e ali nos juntávamos a outras categorias que reivindicavam, então, além de melhores salários, a redemocratização do país, porque ainda estávamos vivendo num regime de ditadura militar.?

Até aí temos uma narrativa standard das manifestações que marcaram os anos finais da ditadura brasileira e a emergência do que ficou conhecido como "novo sindicalismo". Mas o autor continua logo na sequência:

No meu setor tinha dois colegas ex-presos políticos durante a ditadura. Anistiados, voltaram a trabalhar no banco. Eu gostava de conversar com eles a respeito do comportamento dos presos políticos dentro das prisões. Um desses colegas anistiados me contou que, dentro da cadeia, para os presos se satisfazerem sexualmente, passavam um cigarro de maconha de mão em mão e depois faziam um trenzinho em que uns comiam os outros. Esse meu colega disse ser ele o único preso que não participava do tal trenzinho. É claro que na última parte da história dele eu não acreditei. Ele sabia que eu era gay, por isso conversava comigo esses assuntos.

Já sabemos o quanto de homofobia havia nas organizações que combatiam a ditadura no Brasil e em outros países da América Latina. Green, por exemplo, demonstrou que seus integrantes seguidamente associavam práticas dissonantes da heterossexualidade à falta de combatividade para a luta e a desvios "pequeno burgueses" que seriam abolidos com a ascensão do socialismo. ${ }^{8}$ Não sabemos, contudo, se as lembranças do bancário ex-preso político são fidedignas, ou se faziam parte de uma estratégia de aproximação com um colega de trabalho notoriamente gay, ou se as duas coisas ao mesmo tempo, ou se muitas outras mais. De qualquer forma, na narrativa de Almir Dias da Silva, repleta de histórias sobre "pegação", o enredo picante faz todo o sentido. Ele nos atiça a tentar descobrir ou imaginar quem eram os militantes que faziam "trenzinhos" na cadeia. Mas, para além do aspecto anedótico, tal historieta curiosa também participa da história da luta armada e da militância sindical? Quero advogar que sim, desde que transcenda a simples, mas poderosa, curiosidade erótica e seja conectada a um leque mais amplo de experiências, hierarquias e opressões sociais.

$\mathrm{Na}$ continuidade deste artigo, buscarei ressaltar alguns aspectos disso que estou chamando de visão queer ${ }^{9}$ sobre a história do trabalho, a fim de sublinhar a sua importância para a construção de uma perspectiva mais complexa desse campo de estudos, ao permitir refinar a abordagem interseccional a ele dirigida. Voltarei a minha atenção aqui para alguns problemas políticos, conceituais

7 SILVA, Almir Dias da. Dando pinta: memórias de um homossexual. Porto Alegre: Buqui, 2014, p. 94.

8 GREEN, James Naylor. "Who is the Macho Who Wants to Kill Me?: Male Homosexuality, Revolutionary

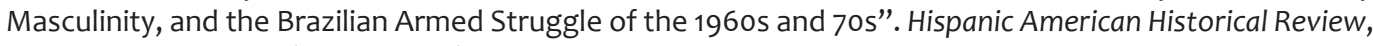
v. 92, n. 3, p. 437-469 (August 2012).

9 Utilizo a expressão "queer" como substantivo (sujeitos desviantes da heteronormatividade) e adjetivo (para qualificar experiências e narrativas), pois essa, apesar de relativamente recente, parece-me expressar uma "asserção politizada da diferença e um conceito unindo uma coalização baseada no dissenso sexual e na variação de gênero". FREEMAN, Susan K.; RUPP, Leila J. "The Ins and Outs of U.S. History. Introducing Students to a queer Past”. In: RUPP, L. J.; FREEMAN, S. K. (ed). Understanding and Teaching U. S. Lesbian, Gay, Bisexual, and Transgender History. Wisconsin: University of Wisconsin Press, 2017, p. 7. A palavra "homossexualidade" e seus derivados, por seu caráter patologizante, só será utilizada como termo "nativo" referente a contextos históricos específicos. O mesmo vale, embora por motivos diferentes (o fato de ser uma designação que emergiu apenas na década de 1980), para a sigla LGBT (Lésbicas, Gays, Bissexuais e Transexuais), embora muitos historiadores e historiadoras se valham dela para abordar períodos anteriores. Por exemplo: CROIX, St. Sukie de la. Chicago Whispers: A History of LGBT Chicago before Stonewall. Madison: University of Wisconsin Press, 2012. 
e metodológicos desta mirada analítica, a partir de exemplos trazidos pela bibliografia e por algumas fontes. Ressalto que não tenho a pretensão de oferecer conclusões prontas e acabadas. Objetivo, sim, delinear um programa coletivo de investigação e incentivar os e as colegas a também se preocuparem com essa pauta, tanto elegendo, para as suas pesquisas, objetos a ela relacionados, quanto levando em conta tal enfoque em suas investigações sobre âmbitos diversos dos mundos do trabalho.

Para iniciar esta discussão, parto de uma reportagem publicada em 1979 pelo jornal Lampião da Esquina, um dos pioneiros da imprensa "homossexual" no Brasil e, certamente, o periódico mais importante com esse perfil no período da redemocratização brasileira. Naquele momento, uma equipe do jornal ficou cinco dias em São Bernardo do Campo, logo após o auge das greves do ABC, entrevistando Lula e a diretoria do Sindicato dos Metalúrgicos. Os jornalistas também estiveram presentes "nas assembleias, no sindicato, nas ruas, procurando ouvir os principais protagonistas da luta no $A B C$ paulista: os operários; e não apenas suas reivindicações, mas também sobre coisas específicas como sexo e prazer". Nessa reportagem, consta em um box o chamado "ABC do Lula", no qual, na letra $\mathrm{H}$, é apresentado o tema: "HOMOSSEXUALISMO NA CLASSE OPERÁRIA" com a curta resposta: "não conheço". ${ }^{10}$ Não há porque duvidar do líder sindical. Provavelmente ele não conhecia mesmo colegas e companheiros cujas práticas e desejos desviassem da heteronormatividade. Afinal, em um setor profissional bastante masculino e machista, associado seguidamente aos valores da força física e da virilidade, aqueles e aquelas que infringiam tais normas certamente não revelavam facilmente em público suas preferências eróticas. Contudo, alguns outros depoimentos presentes no texto do Lampião permitem entrever, ainda que muito indiretamente, pequenas passagens da vida desses desviantes, para quem à opressão de classe (e, em alguns casos, de gênero) se somava a sexual (infelizmente, a fonte escolhida não traz indícios da raça-etnia dos depoentes):

\footnotetext{
Olha, lá na minha seção tem uma moça meio assim, né, ela usa umas roupas meio de homem, não se pinta nem nada. Uma vez ela veio com uns papos meio estranhos para cima de mim, mas não dei muita conversa, né? Fora isso, ela é uma pessoa legal, né, até o chefe da seção tem respeito por ela. Dizem que ela briga muito bem (Marinete de Moraes, montadora).
}

Fresco? Olha, esse negócio de fresco é lá em São Paulo. Aqui eu nunca vi não. É, talvez tenha, mas não põe o nariz para fora da porta, não (Jorge Luis da Silva, ferramenteiro).

O quê, garota? Viado? Olha aqui, viado comigo é na porrada! Não, nunca me fizeram nada, mas é bom eles nem tentar! (Luís Duarte da Rocha, operário).

Viado? Tem sim. Só que dão duro tanto quanto nós, eles têm família também, né? E lá na produção nem tem tempo para viadagem, não. Viado aqui trabalha duro" (João Borges da Silva, operário). ${ }^{11}$

10 Lampião da Esquina, Rio de Janeiro-São Paulo, 14 jul. 1979, p. 10. Caixa alta no original.

11 Lampião da Esquina, Rio de Janeiro-São Paulo, 14 jul. 1979, p. 9-10. 
Interessante destacar, em primeiro lugar, que os entrevistados tiveram seus nomes e sobrenomes citados na reportagem. Portanto, não parecia nada inadequado proferir frases de caráter lesbofóbico e homofóbico. Afinal, tais percepções, muito provavelmente, eram compartilhadas por colegas de trabalho e serviam para demarcar posições e hierarquias no ambiente profissional. Junto aos leitores do Lampião, em geral pessoas brancas de classe média, as declarações confirmavam os preconceitos do operariado e talvez motivassem risos (assustados?).

Sobre a declaração de Lula, ela, por um lado, como dissemos, evidencia a invisibilidade forçada dos "homossexuais" na classe operária e, por outro, a miopia do líder sindical ao tratar dessa questão. Para além do problema "ótico", ou melhor, intimamente articulada a ele, temos também um problema político: a Lula, que então construía a sua liderança e a sua visibilidade para além das fronteiras do Sindicato dos Metalúrgicos e do $A B C$, não interessava fazer ver experiências que poderiam desmoralizar a luta dos trabalhadores aos olhos da sociedade mais ampla, desestabilizando valores e padrões morais compartilhados por diferentes classes sociais. Afinal, de acordo com essa perspectiva, "desvios sexuais" eram incompatíveis com as imagens de luta e abnegação que suscitavam, ao mesmo tempo, admiração e temor em relação ao novo movimento sindical. Os operários Jorge e Luís partilhavam dessa visão (ou da falta dela). O primeiro não "via" os "frescos", mas admitia que eles talvez existissem; já o segundo não duvidava da existência de "viados", mas mantinha-os fora de seu campo de visão sob a ameaça de "porrada". João, por sua vez, era mais complacente: tinha certeza de que "viados" existiam, e bem ao seu lado na fábrica, mas, em função da dureza do trabalho, a "viadagem" daqueles não tinha como se manifestar, ou seja, se tornar visível. Por fim, Marinete foi a que "viu" mais de perto alguém que parecia fugir à heteronormatividade: uma moça "meio assim", com "papos meio estranhos", que, ao que indica a sua historieta, tentou seduzi-la sem sucesso. Apesar de sua condição, ela "Ihe parecia bem legal" e havia, inclusive, angariado respeito no ambiente de trabalho por brigar muito bem, aproximando-se, com a sua performance viril, de valores associados à masculinidade estimados naquele espaço.

Lula, político astuto, sabia que estava sendo entrevistado pela equipe de um jornal homossexual. Não reivindicou a violência contra os desviantes sexuais, talvez nem a apreciasse, preferiu apelar para a invisibilidade do "não conheço". Mas aceitou dar a entrevista e, inclusive, deixar-se fotografar na intimidade, deitado em um pufe de shorts, possibilitando que o Lampião brincasse com a sua masculinidade: “Lula: além de tudo um símbolo sexual?". ${ }^{12}$ Provavelmente, ele foi alvo de muitos comentários jocosos após a publicação da matéria e, imagino, deve ter rido junto com seus companheiros, dizendo algo como: "Tá me estranhando?".

O movimento homossexual (a sigla LGBT ainda não era usada) que se constituía no mesmo período das grandes greves do $A B C$ se dividiu quanto ao apoio ou não aos movimentos dos trabalhadores e trabalhadoras. Sobre isso, James Green, então militante do Somos, o mais importante grupo homossexual da época, ressaltou: "Quando propusemos a participação no $1^{\circ}$ de Maio de 1980 [...] um setor minoritário do Somos se opôs a este engajamento político mais aberto e resolveu abandonar o grupo. Outros perceberam a importância do ato e foram

12 Lampião da Esquina, Rio de Janeiro-São Paulo, 14 jul. 1979, p. 11. 
a São Bernardo com faixas e propaganda - eu, inclusive". ${ }^{13}$ O panfleto distribuído pelo grupo de Green, que se denominou "Comissão de Homossexuais Pró-10 de Maio", tinha títulos como: "Contra a intervenção nos Sindicatos do ABC" e "Contra a discriminação do trabalhador(a) homossexual”. Nele, segundo o militante,

\begin{abstract}
Tentamos elaborar uma crítica sobre a condição dos trabalhadores homossexuais [...]. [...] já naquele momento, apontamos a discriminação na fase da admissão em entrevistas e testes psicológicos etc. Reconhecemos as atitudes discriminatórias na fase de promoção: "quando se descobre que o trabalhador [é] homossexual é impedido de ser promovido". Anotamos que "no dia a dia, quando descoberto, o homossexual tem que produzir mais e melhor sob pena de ser despedido a qualquer pretexto".
\end{abstract}

[...] "somos mandados embora se o patrão souber que somos homossexuais. Ou nem chegamos a ser admitidos. Somos forçados a esconder as nossas preferências fingindo uma padronizada masculinidade (no caso dos homens) ou igual feminilidade (no caso das mulheres) para não sermos alvos de piadas, agressões e isolamento". ${ }^{14}$

Em 1980, Lula declarava que ele não permitiria a exclusão dos homossexuais do Partido dos Trabalhadores. Jogada política? Com certeza. Mas também uma “educação do olhar". Não no sentido de que ele tenha melhorado a sua percepção ótica, mas sim que, no âmbito da própria militância política, aprendeu a incluir no seu campo de visão sujeitos que antes lhe eram invisíveis.

Estou aqui insistindo nas metáforas do olhar e da visão pois elas me parecem repletas de consequências epistemológicas. Joan Scott, em texto crítico à noção da experiência, questiona justamente a "metáfora da visibilidade como transparência literal”" ${ }^{15}$ que pauta boa parte de nossas presunções sobre o conhecimento histórico, como se a ida ao arquivo e a leitura atenta dos documentos nos permitisse ver sujeitos invisíveis e revelar suas experiências. Porém, segundo ela: "A visibilidade da experiência se torna então evidência para o fato da diferença, em vez de se tornar uma forma de explorar como a diferença é estabelecida, como ela opera, e como e de que maneira constitui sujeitos que veem e atuam no mundo". ${ }^{16} \mathrm{Em}$ consequência, para a historiadora, o aspecto unificador da "experiência" excluiria amplos domínios da atividade humana ao simplesmente não considerá-los como experiência, tomando-os como elementos que não trariam nenhuma consequência para a política ou a organização social. ${ }^{17}$ Reivindico que um desses domínios em geral excluídos da experiência dos trabalhadores e trabalhadoras tem sido a "sexualidade", por, aparentemente, não trazer maiores impactos na organização e dinâmica do mundo do trabalho. Assim, vivências como a do "armário", de ir a uma casa de prostituição masculina, de nela ser detido pela polícia e ter que se submeter ao olhar "clínico" e preconceituoso de um doutor, de fazer trenzinhos na prisão e ter que calar sobre isso (ou rir), de ter que permanecer invisível com medo da violência física e simbólica de patrões e colegas de trabalho parecem possuir pouca importância para serem alçadas à condição de experiências dignas de serem

13 GREEN, James Naylor. "Visão retrospectiva: um balanço histórico e memorialístico". Cult, ano 21, n. 235, jun. 2018, p. 26.

14 GREEN. "Visão retrospectiva", p. 26-27.

5 SCOTT, Joan W. “A invisibilidade da experiência”. Projeto História, n. 16, fevereiro, 1998, p. 299-300.

6 SCOTT. "A invisibilidade da experiência”, p. 301-302.

17 SCOTT. "A invisibilidade da experiência", p. 310. 
estudadas, ficando relegadas ao anedotário. Afinal, se a visibilidade de "frescos", "viados" e "moças meio assim" no ambiente de trabalho poderia implicar, na perspectiva de trabalhadores e dirigentes sindicais, perda de respeitabilidade das lutas da classe operária, sua visibilidade nas pesquisas talvez também retire, aos olhos de muitos investigadores e investigadoras, a respeitabilidade desse campo de estudos. No máximo, poderíamos estudá-los como partes de um gueto, ao qual muitos deles e delas permaneceram e permanecem relegados, sem impactos políticos e epistemológicos para o conhecimento histórico de modo mais amplo e, especificamente, para os estudos dos mundos do trabalho. Seguindo Scott, pergunto aqui "como algumas experiências se tornam mais expressivas do que outras [...] e de que modo as diferenças são dissolvidas, a experiência se torna ela própria cumulativa e homogeneizadora, fornecendo o denominador comum sobre o qual a consciência de classe é construída"?. ${ }^{18}$ Afinal, diz ainda a autora, "decidir quais categorias se deve historicizar é inevitavelmente político [...]". ${ }^{19}$

Como o Lula de 1979 e o ferramenteiro Jorge, nós, historiadores e historiadoras do trabalho, em geral não vimos homossexuais, lésbicas, pessoas trans e outros desviantes da heteronormatividade na classe operária, nem nos sindicatos. Alguns talvez tenham visto, mas preferiram desviar o olhar, por julgar esses seres ameaçadores, teórica e politicamente, caso resolvessem tomar o centro do campo de visão. Outros não viram, mas gostariam de ter visto, como Almir, que conta a história dos trenzinhos, podendo, contudo, ser "cegados" pelo riso e pelo escárnio, ou por frases do tipo: "Isso não é importante". Já o "Lampião" fez ver sujeitos outros entre os trabalhadores e trabalhadoras, e também outros desejos que Lula poderia provocar.

Enfim, com todas essas considerações, quero dizer que um olhar queer sobre os mundos do trabalho não depende apenas da descoberta de novas fontes, embora esse também seja um ponto importante, já que a invisibilidade de tais sujeitos, discursos, relações de poder e saber é menos um fenômeno fisiológico do que a consequência epistemológica de relações de poder. Meu próprio olhar para esta questão, mesmo tendo sido eu construído e me construído como gay, não derivou de uma predisposição biológica, de uma "percepção natural”. Claro que minha trajetória individual contribuiu para o meu interesse pelo assunto, mas esse só pôde se colocar a partir de uma decisão política tomada em um contexto de profundos ataques aos direitos e à vida das pessoas LGBTQ e de um "ajuste ótico" proporcionado por leituras, especialmente da bibliografia estadunidense, de textos que procuram, de acordo com um dos pioneiros desse campo, o historiador Allen Bérubé, analisar a relação entre identidade sexual e regimes que regem gênero e raça nos locais de trabalho. ${ }^{20}$

Quero encerrar este artigo colocando ou reforçando algumas proposições sobre a problemática aqui proposta. Primeiro, o objetivo de uma perspectiva queer sobre os mundos do trabalho não é tirar alguns trabalhadores e trabalhadoras do passado do armário, mas compreender, por um lado, como a heteronormatividade "age" sobre os sujeitos que compõem essa classe em diferentes momentos e lugares, estabelecendo hierarquias, conflitos e solidariedades, e, por outro, de que modo a LGBTQfobia se articula com as opressões de classe, raça-etnia, gênero, geração, pertencimento político, religioso, entre outras.

18 SCOTT. "A invisibilidade da experiência", p. 311.

19 SCOTT. "A invisibilidade da experiência”, p. 325.

20 Apud TIEMEYER, Phil. Plane Queer: Labor, Sexuality and AIDS in The History of Male Flight Attendants. Los Angeles: University of California Press, 2013. 
Identificar as trajetórias de "desviantes sexuais" nos ambientes de trabalho e de militância é também importante, tanto em termos políticos como historiográficos. Em seu instigante livro, significativamente intitulado "Out in Union: A Labor History of Queer America”, de 2014, Miriam Frank estabelece uma breve cronologia da história do trabalho LGBT estadunidense de 1965 a 1985, identificando personagens e acontecimentos significativos para esse recorte. Para 1969, por exemplo, ela menciona a trajetória de Bill Olwell, um homem gay "no armário", que se apresentou para a reeleição como presidente do Conselho de Trabalho do Condado de King, em Seattle. Sua influência se expandiu para além da sua esfera associativa inicial dos escriturários do varejo. Suas manifestações públicas contra a guerra no Vietnã e a favor da integração racial no setor de comércio provocaram a ira de outros dirigentes sindicais, os quais encontraram um candidato para se opor a ele e financiaram uma campanha de insinuações sobre a sua sexualidade. Olwell, em contrapartida, expôs o conjunto dos excelentes serviços que prestou à categoria e foi reeleito. Depois disso, ele nunca mais escondeu a sua condição de homem gay. ${ }^{21}$

Histórias como essas possibilitam, por um lado, demonstrar a importância da atuação de pessoas LGBTQ nos mundos do trabalho, evidenciando a sua pluralidade, a maneira como os preconceitos contra esses indivíduos influencia nas disputas políticas internas à classe e também as resistências por eles e elas empreendidas contra tais opressões. Favorecem também uma imagem mais inclusiva da própria representação da classe trabalhadora, possibilitando identificações e recrutamentos, com todas as tensões deles decorrentes. Quem são os Bill Olwell da história brasileira? São muito diferentes de seus congêneres estadunidenses? De que maneira as especificidades das hierarquias de classe, raça, gênero e sexualidade no Brasil conformam esses sujeitos e suas experiências?

Porém, me parece que identificar experiências de sujeitos desviantes sexuais no ambiente laboral e sindical não é suficiente. Também temos que nos instrumentalizar para perceber os subtextos queer nas práticas discursivas e não discursivas de patrões e patroas, trabalhadores e trabalhadoras, políticos e políticas, entre outros segmentos sociais. O que significa, por exemplo, para empregados designados no nascimento como homens atuarem em profissões consideradas próximas de atributos femininos como aquelas relacionadas ao cuidado e à estética? Penso, por exemplo, nos trabalhadores domésticos, enfermeiros, professores primários, comissários de bordo, cabeleireiros, maquiadores, estilistas, entre outros. Como a queerness (ou "viadagem", ou "bichice") dessas atividades estabelece hierarquias nos ambientes de trabalho e na organização sindical? De outro lado, de que modo tais profissões despontam como possibilidades, muitas vezes únicas, de ascensão social? Penso, por exemplo, no papel dos salões de beleza para que mulheres trans pudessem conhecer pessoas famosas, as quais Ihes garantiram recursos materiais, prestígio e até mesmo projeção artística (esse é o caso da famosa artista transformista Rogéria, entre outras ${ }^{22}$ ). De outro lado, como pessoas designadas como mulheres no nascimento tiveram suas experiências condicionadas pelo fato de labutarem em setores ligados a atributos ditos masculinos, como a metalurgia e a mineração? De modo mais amplo, de que modo profissões se tornaram femininas, masculinas ou queer?

21 FRANK, Miriam. Out in Union: A Labor History of Queer America. Philadelphia: Temple University Press, 2014, p. xiii.

22 PASCHOAL, Marcio. Rogéria: uma mulher e mais um pouco. Rio de Janeiro: Estação Brasil, 2016. 
O livro de Phil Tiemeyer, "Plane Queer: Labor, Sexuality and AIDS in The History of Male Flight Attendants", de 2013, é exemplar nesse sentido. O autor, por exemplo, analisa um material publicitário publicado na revista da companhia aérea estadunidense Pan American na década de 1930, na qual se destaca a imagem de "Rodney: o comissário sorridente". Para Tiemeyer, a campanha acentuou as características mais suaves do comissário, especialmente sua aparência elegante, adornada por seu uniforme preto-e-branco com reflexos vermelhos: "Com o sorriso e a cabeça levemente inclinada, Rodney combinava atratividade juvenil e uma acessibilidade que convidava as pessoas a valorizá-lo, colocando-o, assim, no papel fictício feminilizado de um sedutor objeto sexual". Tal representação se opunha às imagens mais difundidas da masculinidade da classe trabalhadora: as dos musculosos operários e trabalhadores agrícolas brancos ou de carregadores de trem negros, ajudantes de garçom e afins. ${ }^{23}$ Dessa forma, menos importante do que afirmar se Rodney e os demais comissários de bordo "eram" ou não, é apontar para as simbologias e ambiguidades de gênero associadas a determinadas profissões, as quais, certamente, incidem sobre aqueles e aquelas que as exercem, sobre seus e suas colegas de trabalho, representantes sindicais, patrões etc., condicionando formas específicas de dominação e resistência.

Por fim, uma breve observação sobre as fontes. Insisto que não considero a escassez de menções explícitas à "sexualidade" dos trabalhadores e trabalhadoras o maior entrave para o desenvolvimento de uma perspectiva queer sobre a história do trabalho no Brasil (na mesma direção do que disse Álvaro Pereira Nascimento em relação aos trabalhadores e trabalhadoras negras). ${ }^{24}$ Também, nesse caso, me parece, cabe aos historiadores e historiadoras do trabalho estarem com tal questão na cabeça para que possam, como já o fizeram em relação a várias outras problemáticas (raça-etnia, gênero, vida cotidiana, corpo, lazer etc.), "inventar”, com muita criatividade, fontes para as suas pesquisas que levem em conta também os desejos e práticas não heteronormativas de seus personagens. Se muitas questões não puderem ser respondidas, também nesse caso o silêncio é eloquente e deve ser interpretado. Contudo, aqui deve-se considerar a já citada advertência de Eve Sedgwick para o fato de que "mesmo num nível individual, até entre as pessoas mais assumidamente gays [e, acrescento, lésbicas, bissexuais e, com certas diferenças, trans] há pouquíssimas que não estejam no armário com alguém que seja pessoal, econômica ou institucionalmente importante para elas". 25 Portanto, se a falta de menções à cor em muitos documentos dificulta a vida dos pesquisadores e pesquisadoras, no que tange à questão tratada no presente texto as barreiras parecem se mostrar ainda mais complicadas. Da mesma forma, a análise de nomes e práticas de nominação sugerida por Nascimento ${ }^{26}$ para acompanhar arranjos sociais de pessoas negras não me parece adequada ao recorte do qual estamos tratando, já que sexualidades dissidentes não se articulam em linhagens e descendências. Ao contrário, no caso das pessoas trans, e mesmo, em alguns casos, de lésbicas ou gays, o uso de nomes com significado de gênero contrários àquele designado no nascimento muitas vezes impede o acompanhamento de trajetórias individuais e coletivas. Por outro lado, em alguns processos judiciais (e também na imprensa, sobretudo nas colunas policiais), à custa de uma incrível violência simbólica, pessoas que optaram serem chamadas por nomes que consideramos

23 TIEMEYER. "Plane Queer".

24 NASCIMENTO, Álvaro Pereira. "Trabalhadores negros e o 'paradigma da ausência': contribuições à História Social do Trabalho no Brasil”. Estudos Históricos, Rio de Janeiro, v. 29, n. 59, p. 607-626, set.-dez. 2016.

25 SEDGWICK. "A epistemologia do armário", p. 22.

26 NASCIMENTO. “Trabalhadores negros e o “paradigma da ausência”, p. 621. 
femininos são reconduzidas aos nomes que lhes foram dados no nascimento. Esse é o caso, por exemplo, de Margarida, processada em outubro de 1975 na cidade de Porto Alegre "sob acusação de vadiagem e importunação ofensiva ao pudor", cujo nome "verdadeiro" é assinalado no documento (e que eu não reproduzo aqui por respeito a ela).

Vou me estender um pouco mais sobre o caso de Margarida. O processo afirma que ela era "homossexual já conhecido [no masculino!] dos policiais" e que já havia sido detida diversas vezes. Em março daquele mesmo ano, teria assinado "termo de tomar ocupação", mas, segundo o auto, continuou "na ociosidade", fazendo “"trottoir' masculino", pelo que foi presa novamente. Quando interrogada, afirmou ser camareira, mas que não estava trabalhando. Disse que, da última vez em que foi liberada, trabalhou como “"doméstico' em casa de família” e por último em um "Rende vus (sic) em serviço de limpeza", mas que em nenhum dos locais quiseram assinar sua carteira. Afirmou igualmente que fazia 13 dias que "não trabalhava", tirando seu sustento da prostituição. Ressaltou que sempre trabalhou como "doméstico" ou em serviços de limpeza, mas que nesses empregos nunca quiseram assinar sua carteira, e que, ainda que tivesse deficiências físicas na mão e perna direitas por conta de paralisia infantil, considerava-se capaz para trabalho doméstico ou para ser camareiro. Disse ainda que começou a fazer "o 'trottoir' travestido em março do corrente ano [1975]", afirmando não cobrar preço fixo por seus programas, mas que os clientes costumam pagar de 50 a 100 cruzeiros, às vezes até mais. Na seção de informações sobre sua vida pregressa, sua situação econômica foi definida como “pobre”. Uma observação importante: Margarida é apontada no documento como "de cor mista". ${ }^{27}$

Temos aqui um trágico exemplo no qual se evidenciam as intersecções de opressões de classe, raça, gênero, sexualidade e deficiência física. Talvez caiba a nós, então, considerar Margarida como uma integrante de pleno direito dos mundos do trabalho. Afinal, como lembrou uma travesti que "batia calçada" diante de um dormitório de operários da construção civil, no Rio de Janeiro, ao explicar ao jornal Lampião em 1979 o porquê desses trabalhadores não estranharem a sua atividade: "Bater calçada ou carregar sacos de cimento nas costas é tudo a mesma exploração; eles sabem que a gente está aqui trabalhando - deve ser isso o que chamam de consciência de classe". ${ }^{28}$

Recebido em 13/11/2018

Aprovado em 27/11/2018

27 Processo contra X (nome de registro), conhecida como Margarida, sob acusação de vadiagem e importunação ofensiva ao pudor, outubro de 1975, TJ-RS.

28 Lampião da Esquina, Rio de Janeiro-São Paulo, 14 jul. 1979, p. 11. 
